Fig. 8. Längsschnitt durch eine dickere Hodenröhre im Bereich der Keimzone.

Fig. 9. Kern in Vorbereitung zur Theilung mit Fadenbildung von einem Urei aus der Keimzone des Eierstocks.

Fig. 10. Urei aus der Keimzone von Ascaris megalocephala bivalens. Spindel mit vier Mutterschleifen.

Fig. 11. Desgleichen mit vier Mutterschleifen, die sich in Tochterschleifen gespalten haben.

Fig. 12 u. 13. Ureier aus der Keimzone von Ascaris megalocephala univalens mit zwei Mutterschleifen. Fig. 12 bei seitlicher Ansicht der Spindel. Fig. 13 bei Ansicht der Spindel vom Pol aus.

Fig. 14. Urei aus der Keinzone von Asearis megalocephala bivalens mit vier Mutterschleifen vom $\mathrm{Pol}$ der Spindel ans gesehen.

Fig. 15. Zu einem Bündel angeordnete vier chromatische Elemente vom Ei von Ascaris megalocephala bivalens kurze Zeit nach der Befruchtung nach Auflösung der Membran des Keimblisschens.

Fig. 16. Zwei Bündel von je vier chromatischen Elementen aus einem Ei von Ascaris megalocephala bivalens kurze Zeit nach der Befruchtung und nach Auflösung der Kernmembran.

Fig. 17. Desgleichen bei ctwas anderer Lage der Bündel.

Fig. 18. Drei Zwischenkörperchen aus dem Anfang der Eiröhre von Asearis megalocephala.

\title{
Die Entwicklung der Urnieren beim Menschen.
}

Von

Dr. Hans Meyer,

Docent der Geburtshülfe und Gynïkologie in Zürich.

Hierzu Tafel $V$ u. VI.

Die embryologische Forschung ist durch die neueren Fortschritte der mikroskopisehen Technik bedeutend erleichtert und die Zuverlässigkeit ihrer Ergebnisse wesentlich erhöht worden. Verbesserte Methoden der Fixirung, Härtung und Einbettung, der Schnittführung und Färbung erlauben heutzutage Resultate zu erreichen, welche vor 10 Jahren Glück, Geschick und Ausdauer 
vereint nicht zu Stande brachten. Fehlerlose Serien feinster Schnitte von Embryonen jeden Alters werden fast spielend hergestellt. - Diesen Fortschritten ist es grösstentheils zu verdanken, dass das Studium der ersten Organanlagen durch fast alle Thierklassen hindurch in den letzten Jahren mit so viel Eifer und Erfolg an Hand genommen wurde.

Die Embryologie des Menschen musste dabei aus nahe liegenden Gründen etwas zu kul'z kommen. Das verwerthbare Untersuchungsmaterial, welches dem einzelnen Forscher durch Zufall und gutes Glück in die Hände fällt, ist eben immer nur spärlich und steht in Bezug auf den Erhaltungszustand meist hinter dem leicht zu gewinnenden Material von Thieren zurück. lnsbesondere gilt dies von den frühesten Entwicklungsstufen.

Die aus den ersten Schwangerschaftsmonaten stammenden Embryonen können nur dann von vorneherein als wohlerhalten und für die mikroskopische Untersuchung vollkommen brauchbar gelten, wenn man entweder Gelegenheit hatte, das $\mathrm{Ei}$ noch in utero eingeschlossen, durch eine Exstirpatio uteri zul gewinnen, oder wenn dasselbe in Folge Einwirkung einer groben mechanischen Gewalt sich gelöst und nach Berstung der Decidua reflexa, ohne die Abschälung des Decidua-Sackes abzuwarten, ausgetreten war. Wenn längere Zeit vor der Ausstossung blutiger Abfluss bestand, die Lösung des Eies also nur nach und nach durch Trennung in der Decidua erfolgte, so kommt man mit grösster Wahrscheinlichkeit nicht zu einem frischen, für die Untersuchung untadelhaften Embryo. Entweder war er in utero abgestorben, während das $\mathrm{Ei}$ theilweise weiter ernährt wurde, oder er ist, nachdem die Fruchtblase, vielleicht in Folge krankhaft gesteigerter Absonderung von Inhaltsfluissigkeit oder Entartung der Eihäute, gesprungen war, herausgeschwemmt worden und unfehlbar verloren gegangen. Im ersteren Falle findet man hie und da einen gelblichen, spröden Embryo, welcher trotz Erhaltung der äusseren Gestalt ganz untaugliche mikroskopische Bilder gibt; meist aber ist er defect oder die unversehrte Fruchthülle enthält nur einzelne Bruchstücke, andere Male auch nicht eine Spur von einem Embryo: er ist zerfallen und resorbirt worden. Mit dem zweiten Falle haben wir es meist zu thun, wenn im Innern des geborstenen Eies nur noch der Stummel eines Nabelstranges angetroffen wird.

Es kommt noch dazt, dass gar leicht so zarte Gebilde, wie 
jüngste Embryonen sie darstellen, durch zu lange oder ungeeignete Conservirung leiden.

Deshalb sollte stets der Schilderung eines Embryo, welche auf volle Berïcksichtigung Anspruch machen will, eine Angabe über die Herkunft der Frucht, über den Verlanf des Abortus und jedenfalls über die Methoden der Conservirung und die weitere Behandlung beigefügt werden. - Zur Gewinnung einer zuverlässigen Seala für die Altersbestimmung so junger Embryonen wäre eine Messung im frischen Zustande oder doch nach Einwirkung solcher Reagentien, deren schrumpfende Wirkung auf die Gewebe im Allgemeinen bekannt ist, sehr wünschenswerth. Das Maass sollte stets, nach der üblichen Weise, durch die längste Gerade, welche durch den Embryo gezogen werden kann, mit Bezeichnung ihrer Endpunkte, ausgedrütekt werden.

Nachdem ich in weit über liundert Abortiveiern, welche ich in den letzten Jahren in frischem Zustande zu untersuchen Gelegenheit hatte, erfolglos nach einem brauchbaren Embryo ans dem ersten Schwangerschaftsmonate gesucht hatte, spielte mir der Zufall in letzter Zeit kwz nach cinander zwei solche Embryonen in ganz untadelhaftem Zustande in die Hände. Der eine derselben ist zugleich der juingste, den ich je zu sehen bekommen habe. Ich gewann ihn durch künstlichen Abortus bei einer Fran, die wegen einer Gesehwulst kein lebendes Kind gebären konnte.

Nachdem die Periode, welche sonst nach 4 , hie und dir nach 5 Wochen einzutreten ptlerte, 18 Tage über die 4 Wochen ausgeblieben war, wurde eine mit nasser Watte umwickelte Sonde in's cavum uteri eingeführt und einige Male vor und zuritckgezogen und herumgedreht; bierauf ein dicker Laminariastift eingelegt. Nach etwa 10 Stunden erfolgten Welien, welche aber nach Entfernung der Laminaria wieder fast gan\% sistirten. Erst am nächsten Tagee wurde das unversehrte Ei, olne den Deciduasack, geboren.

Das Ei stellte ein zottiges Säckchen voll $22 \mathrm{~mm}$ Durchmesser dar. Nur an einer etwas iiber linsengrossen Stelle fehlten die Zotten fast ganz, so dass durch dieses Fensterchen der Inhalt überschaut werden konnte. $\mathrm{Er}$ bestand aus einer wasserklaren Flïssigkeit, in welcher ein win\%ig kleiner Fötus flottirte. Man mochte aber das Ei drehen, wie man wollte, der Embryo 
blieb stets an einer bestimmten Wandstelle liegen. - Bei Eröffnung des Chorions floss das Wasser ab; der Embryo blieb an seinem Platze am Chorion laften; ein kurzer, dicker, aber wegen seiner vollkommenen Durchsichtigkeit kanm wahrnehmbarer Stiel verband ihn dort mit der Innenfläche des Chorion.

Das sehr zarte Amnion lag dem Fötus ganz dicht au. Ein wässeriger Inhalt desselben war nicht zu constatiren. Das Nabelbläschen, ein schlaff angefülltes, etwa $4 \mathrm{~mm}$ breites Säckchen, war kurz gestielt. Eine freie Allantois konnte nicht wahrgenommen werden.

Der Embryo selbst maass vom Scheitelhöcker zur Steisskrümmung $4,25 \mathrm{~mm}$. Eine ideale Längsachse vom Vorderkopf zum Schwanzende an dem aus den Querschnitten reconstruirten Embryo ergab eine Länge von 6,04 mm. Er besass schneeweisse Farbe und war nur stellenweise durchsichtig. Seine Consistenz war, aus dem Verhalten beim Umwenden in sehr wenig Flüssigkeit zu schliessen, ziemlich derb.

Mit Benützung der Lupe und unter Zuhilfenahme der Reconstruction aus den mikroskopischen Schnitten stellte ich die auf Tafel V, Fig. 1, dargestellte Skizze des im Amnion eingeschlossenen Embryo her. - Ueber die äussere Gestalt liessen sich folgende Einzelheiten erheben.

In einem Winkel, welcher wenig mehr als ein rechter beträgt, stossen Kopf- und Rumpftheil des Embryo in der Nackenkrümmung zusammen. Die beiden Schenkel dieses Winkels zeigen fast gestreckten Verlauf. Dem Rumpftheil schliessen sich in fast kreisrunder Krümmung die Beckengegend und das Schwanzende an. Der Rumpftheil, Becken und Schwanz abgerechnet, übertrifft den Kopftheil nur um weniges an Länge; an Masse steht er weit hinter demselben zurtick. Seine obere Hälfte wird durch die Vorwölbung des Herzens etwas ansehnlicher; Banchund Lendenabschnitt sind sehr schlank.

An der Gestalt des Vorderkopfes kann man bereits das Mittelhirn an der Bildung des Scheitelhöckers erkennen. Das vorderste Ende des Kopfes mit dem Vorderhirn überragt den Eingang in das Darmrohr. Seitlich wird die zum Munde bestimmte Oeffuing von den noch weit von einander abstehenden Oberkieferfortsätzen begrenzt. Letztere sind durch eine Furche von den einander schon ziemlich nahe tretenden Unterkieferfortsätzen ge- 
trennt. Darauf folgen nach unten die am meisten vortretenden Zungenbeinbogen; dann der kleine dritte Kiemenbogen. Der vierte Bogen ist nicht erkennbar; selbst auf den mikroskopischen Bildern ist er nur als kleine, gefässhaltige Hervorragung wahrzunehmen.

Die Anlage des Herzens bildet einen breiten, ventralwärts abgerundeten Wulst, welcher, nach den Schnitten, ein wenig nach links hinübergedrängt erscheint.

Das Schwanzende überragt den eigentlichen Beckentheil, d. h. die nach unten abgeschlossene Bauchhöhle um 0,6 mm. An seiner Basis, also am Uebergang des Beckentheils in's Schwanzstück, bezeichnet ein ventral- tnd lateralwärts vorragender kleiner rundlicher Wulst die Anlage der unteren Extremitait. Von der oberen Extremität ist keine Andeutung zu schen.

Am Rumpf- and Beckentheile \%eichnen sich jeclerseits vier längsverlaufende, durch seichte Furchen markirte Zonen. Die unpaare, schmale Rückenzone entspricht dem Centralnervensystem; die nächste zeigt deutliche Segmentirung ${ }^{1}$ ) und liegt über der Segmentalplatte. Die dritte bezeichnet eine Ausbuchtung der Bauchwand an der Stelle, wo die Wolff'schen Körper liegen. Die vierte entspricht dem Uebergang der Bauchwand in den Bauchstiel.

Weder Kopf- noch Sehwanzende weichen von der Sagittalebene ab. Die Randzone der Banchwand ist in der ganzen Länge der Beckengegend rinnenartig eingedellt.

Das Darmrohr steht noch in offener Verbindung mit der Nabelblase. Die Oeffnung desselben ist ein $0,03 \mathrm{~mm}$ breiter und 0,06 mm langer, in der Körperlänge liegender Schlitz. — Der Nabel, d. h. die noch nicht geschlossene Bauchwand, deren Ränder in's Amnion übergehen, bildet eine weite, schlitzartige Oeffnung. Sie beginnt hinten, unmittelbar hinter dem Austritt der Allantois und ihrer Gefässe, erweitert sich am Bauchtheil sehr bedeutend und läuft dann nach vorn allmählich wieder aus, so zwar, dass fast das ganze untere Drittel des Herzens durch eine breite Spalte zu sehen ist (s. Fig. 1).

Was das Alter des Embryo betrifft, so deutet seine geringe Grösse und Entwicklung darauf hin, dass das Ei, aus dem er

1) Ich habe versïumt, die Segmente zu ziihlen. 
hervorgegangen ist, gewiss nicht bei der zuletzt eingetretenen Periode ausgestossen wurde, sondern von der zuerst ausgebliebenen Menstruation stammt. $\mathrm{Er}$ ist demnach mindestens 18 und höchstens 21 Tage alt. Einen Fehler könnte in diese Berechnung nur der Umstand bringen, dass bei der betreffenden Frau vielleicht auch dies Mal, wie schon zu wiederholten Malen früher, der Eintritt der Periode erst nach 5 Wochen erfolgt wäre. In diesem Falle könnte dann der Embryo noch jünger geschätzt werden.

Der II. Embryo ist etwas älter als der eben beschriebene. $\mathrm{Er}$ ging am 28. Tage nach der erst ausgebliebenen Periode, wie mir die Frau angab, in Folge eines Sturzes ab. Das unversehrte Ovulum fand ich mit wenig geronnenem Blut in der Vagina, als ich die Frau, welche zum ersten Mal zwei Jahre vorher mit der Zange entbunden worden war, etwa 24 Stunden nach dem angeblichen Fall wegen heftiger Kreuzschmerzen und leichter Blutung untersuchte. Doppelseitige tiefe Cervicalrisse, von der ersten Geburt herrührend, hatten offenbar die Ausstossung des aus der Decidua gelösten Eies erleichtert.

Das Ei hatte $4^{1} / 2 \mathrm{~cm}$ im Durchmesser und war nur an einer kleinen Stelle von Zotten entblösst. Durch das vollkommen durchsichtige Chorion sah man in der wasserklaren Chorionflüssigkeit den Foetus schwimmen; an einem kurzen Stiel war er an einer Stelle der Wandung befestigt.

Fig. 2 auf Tafel $\mathrm{V}$ gibt ein Bild des Embryo. Er ist von einem nux wenig abgehobenen, zarten Amnion, in dessen Inneren wiederum keine Fliissigkeit constatirt werden konnte, umhüllt. Der Bauchstiel ist dick und ganz durchsichtig. In ihm verläuft ein dünner, $6 \mathrm{~mm}$ langer Faden zu dem $5 \mathrm{~mm}$ breiten, rundlichen Nabelbläschen. Wie die Reconstruction ergibt, erweitert sich die Allantois ausserhalb des Körpers spindelartig, um dann spitz zulaufend zu enden (s. Fig. 2). Dabei ist sie aber ganz im Gewebe des Bauchstiels eingeschlossen.

Der Embryo misst $8 \mathrm{~mm}$, von der Nacken- zur Steisskrümmung. Die ideale Längsachse vom Vorderkopf zum Schwanzende beträgt an dem aus den Querschnitten reconstruirten Embryo 13,33 mm. Er zeigt weisse Farbe; nur das Herz sticht als braunschwarzer Wulst hervor. Seine Consistenz ist derb, so dass sich beim Umdrehen seine Gestalt nicht verändert. - Seine Aufrollung 
ist im Vergleich zu derjenigen des jüngeren Embryo in der Art beträichtlicher geworden, dass za der ungeführ gleich starken Nacken- und Steisskrummung sowohl am Kopf-, als am Rumpftheil, an beiden ungeführ in der Mitte, neuc Krummnngen hinzugekommen sind. Zugleich hat sich das Schwanzende verlängert. Dadurch haben sich Kopf und Schwanz fast bis zur Berührung genähert. Beide Extremitäten sind als kleine flossenartige Stummel ohne irgend welche Gliederung angelegt. Die Anlage der Augen ist deutlich zu sehen. Der Banchstiel geht nach rechts ab und bedeckt bei der Ansicht von rechts das nach links gewendete Schwanzende. Das Kopfende ist nur ganz wenig nach rechts geneigt. Das Darmrohr ist ganz geschlossen.

Der Nabel hat sich bedeutend verkleinert. Der Ansatz des Amnion schliesst sich an den Austritt der Nabelgefässe und den feinen ductus omphalo entericus an.

Das Alter dieses Embryo ist nach den Angaben der Frau anf 28-31 Tage anzusetzen. Auch dieser muss, der Entwicklung nach zu urtheilen, einem bei der zuerst ausgebliebenen Menstruation abgelösten Ei entstammen.

Es ist noch nicht so lange her, dass man so seltene Präparate, wie unversehrte menschliche Eier aus dem ersten Schwangerschaftsmonat, einfach als Cabinetstiicke aufbewahrte oder einem Embryologen von Fach in mehr oder weniger gutem Zustande einlieferte. Heutzutage eröffinet uns die Vervollkommnung der Mikroskopie im letzten Decennium so verlockende Aussichten auf Entdeckung neuer Thatsachen in einem Gebiete, welches fast ausschliesslich auf die mikroskopische Untersuchung angewiesen ist, dass wir es nicht iiber uns bringen, solche Stücke unangetastet in den Prïparatenschrank zu stellen. Die mikroskopische Technik ist aber auch dermassen Allgemeingut geworden, dass derjenige, welcher es unternimmt, solch werthvolle Objecte selbst zu untersuchen, nicht von vorneherein des Vandalismus bezichtigt werden darf.

Bei der mikroskopischen Untersuchung meiner Embryonen zog ich das vorzligliche Verfahren in Anwendung, welches Herr Prof. Gaule in Zürich nunmehr für alle frischen Präparate benützt. Sie werden nach Eröffnung des Chorions sofort mit einer stets vorräthig gehaltenen concentrirten wässerigen Sublimatlösung übergossen, nach 5 Minuten leicht abgewaschen, dann fuir 12 Stunden in $70 \%$ igen und hernach fitr ebenso lange in 
absoluten Alkohol gelegt; hierauf nach bekannter Methode in Xylol-Paraffin eingelegt. Mittelst Mikrotom wurden die Embryonen in lückenlose Serien von 0,01 mm dicken Querschnitten zerlegt, diese möglichst dicht gedrängt neben einander auf Objectträger aufgelegt, nit einem in Alkohol getränkten Pinsel leicht angedriickt, hierauf des Paraffins entledigt, der Reihe nach in Hämatoxylin, Nigrosin, Safranin, Eosin gefärbt und in XylolCanadabalsam aufbewahrt.

Der jüngere Embryo ergab 252 Schnitte, was einer Länge von $2,52 \mathrm{~mm}$ entsprechen würde, während sie am frischen Embryo $4,25 \mathrm{~mm}$ gemessen hatte. Nach einer Mittheilutg ron Herm Prof. Ganle erfahren die nach seiner Methode behandelten Objecte eine Verkürzung von einem Drittel des ursprünglichen Maasses. Der Ausfall von annähernd $2 / 5$ bei unserem Embryo ist gewiss zum grössten Theil auf den Umstand zurtickzuführen, dass der Embryo, um ihn in der Vorlesung demonstriren zu können, 3 Tage lang in Alkohol liegen gelassen wurde. Vielleicht ist das foetale Gewebe in diesem Alter auch besonders retractionsfähig. In einer fehlerhaften Schnittrichtung kann die Ursache nicht gesucht werden; denn, abgesehen von einer sehr unbedeutenden Seitenneigung, scheint sie geradezu ideal ausgefallen zu sein.

Der Embryo II ergab 540 Schnitte. Die reconstruirte Länge von 5,40 mm zeigt also ungefähr eine Verkürzung um ein Drittel der ursprünglichen Länge.

Von beiden Embryonen reconstruirte ich aus den Querschnitten theils die Körperform mittelst Carton, theils ideale Längsschnitte sowohl des Ganzen, als einzelner Organe. Zunächst beschäftigte mich die Anlage des Urogenitalsystems. Ich theile in Folgendem die Resultate meiner Untersuchung, welche ich auf die Urnieren beschränken konnte, mit, und schicke eine Zusammenfassung desjenigen, was in der Litteratur des letzten Decenniums über die erste Entwicklung der Urnieren beim Menschen bekannt geworden ist, voraus. Es ist ziemlich spärlich.

$\mathrm{His}$ in seinem klassischen Werke "Anatomie menschlicher Embryonen" erwähnt bei der Schilderung seiner jüngsten Embryonen S.R und E gar nichts vom Urogenitalsystem. Bei Embryo L., welcher nach langer Aufbewahrung in Alkohol noch 2,4 mm malss, findet er das Urogenitalsystem als eylindrischen Gang, der wenigstens an einigen der Schnitte zul constatiren ist, angelegt. 
Bei Embryo M., welcher nach Jahre langer Aufbewahrung in Alkohol noch 2,6 mm lang war, constatirt er zwischen seitlicher Leibeswand und der breiten Wurzel des Gekröses eine niedrige Leiste mit Epitheldecke. Der untere Theil der Leiste enthïlt die Urnierenanlage, die sich als Zelleylinder von $25-35 \mu$ darstellt. Hinten und seitlich von ihr verläuft die noch sehr enge vena cardinalis. Das untere Ende ist nicht zu beobachten; das obere Ende reicht nicht so weit hinauf, wie das obere Ende der Leiste, die bis zur Decke der Rumpfhöhle hinaufreicht.

Bei dem in frischem Zustande $4 \mathrm{~mm}$ langen Embryo $\alpha$ findet er die Urniere in der ganzen Liinge angelegt in einer gerundeten Längsleiste. Der obere Theil zeigt Sförmige gebogene Kanäle, an denen das Kapselstück jedoch noch nicht von Gefässknäueln eingestülpt erscheint. Letztere sind erst insoweit angelegt, als an der medialen Hälfte der Leiste dichtere Zellanhäufungen liegen, in welche man kleine Zweige der Aorta eintreten sieht. Die untere Hialfte der Leiste enthält anstatt der gebogenen Röhrchen einen $\mathrm{seh} r$ weiten, dickwandigen Kanal, der den Raum der Leiste zum grösseren Theil ausfiillt. Seine Wanddicke beträgt fast das Doppelte von derjenigen des spätern Wolff'schen Ganges. Bis jetzt ist $\mathrm{Hi}$ bei keinem seiner menschlichen Embryonen auf Bilder gestossen, welche selbständige Entstehung der UrnierenkanäIchen zu zeigen vermochten. Der Wolff'sche Gang tritt unterhalb des Darms in geschwungenem Bogen in den Beckentheil des Körpers und er mündet hier in die Seitenwand der Cloake ein. Von einem neben der Einmündungsstelle abgehenden Blindsack hat er keine Andeutung gesehen.

Von den ca. 4 Wochen alten Embryonen $A$ und $B$ berichtet er über das Urnierensystem Folgendes : Dasselbe besteht aus dem Wolff'schen Gang, aus den in ihn einmündenden Querkanälen und aus den mit letzteren verbundenen Gefässkn:iueln. Diese Theile sind in eine $0,3-0,4 \mathrm{~mm}$ breite, gerundete Leiste, die Urnierenleiste, eingeschlossen, welche jederseits neben der Ábgangsstelle des Magen- und Darmgekröses der hinteren Rumpfwand entlang läuft. Dieselbe ist von einem einschichtigen Epithel überkleidet und ausser den Gebilden der Urniere selbst enthält sie die hinter ihnen liegende Cardinalvene. Das untere Ende der Urnierenleiste tritt in einem nach abwïrts convexen Bogen zur vorderen Bauchwand; es leitet den Wolff'schen Gang zur Cloake und verliert sich neben dieser letzteren. Nach oben hin steigt die Urnierenleiste höher hinauf als die Urniere selbst, sie erreicht die Decke der Rumpfhöhle; mit der von ihr umschlossenen Cardinalvene tritt sie nach vorn und trifft auf den gleichfalls in einer besonderen Leiste eingeschlossenen, der Seitenwand des Rumpfes folgenden Cuvier'schen Gang.

Der Wolff'sche Gang liegt innerhalb der Unnierenleiste am meisten lateralwärts, dicht unter der Epitheldecke. Sein Gesammtdurchmesser beträgt in den mittleren Abschnitten des Organs gegen 60 , die Lichtung gegen $40 \mu$. Seine mediale Wand nimmt die nux etwa 
$20 \mu$ im Durchmesser fassenden Enden der Querkanälchen auf, deren spindelförmige Lichtung ohne vorherige Ausweitung direct in jenen ausmündet.

Jedes Urnierenkanälchen besteht aus drei quergestellten und in scharfem Zickzack zusammengebogenen Schenkeln, einem hinteren, mittleren und vorderen. Der hintere, cylindrisch von Gestalt, vermittelt die Verbindung mit dem Wolff'schen Gang; der mittlere ist etwas spindelförmig aufgetrieben, sein verjüngtes :iusseres Ende biegt in den vorderen Schenkel um, der als enges Rohr beginnt, dann aber zu einer geräumigen, den Glomerulus umschliessenden Kapsel sich ausweitet. Die Zellen, welche die Kapsel bilden, sind dünner als die des übrigen Rohres, die in den Kapselraum hervortretende Oberfläche des Gefässknäuels ist von einer besonderen Epithelschicht bekleidet. Es liegen die Gefässknäuel in der medialen Hälfte der Nierenleiste; sie werden durch kleine, direct aus der Aorta kommende Arterienzweige gespeist und bogenförmige Venenzweige führen das Blut nach der Cardinalvene zurück. Die geschilderten Verhältnisse finden sich bis in die Nähe des obern Endes der Urnieren, d. h. bis in die Höhe des untern Lungenrandes. In diesem obern Abschnitt sind die Kanäle kürzer, die Knäuel und die Kapseln kleiner als im Mittelstücke der Drüse. Das untere Ende der letzteren ist an beiden Schnittreihen schräg, bezw. frontal getroffen und es lässt sich nicht erkennen, ob die in ihm befindlichen Röhrchen schon ihre volle Ausbildung erhalten haben. Im Uebrigen ist der Wolff'sche Gang bis in die Nïhe seines vorderen ${ }^{1}$ ) Endes mit Urnierenkanälchen besetzt. Dies vordere ${ }^{1}$ ) Ende des Wolff'schen Ganges biegt steil in die Höhe und verliuft ein kleines Stück weit neben der Cloake, bevor die Einmündung erfolgt. An der Stelle der letzteren zeigt sich die Cloake mit zwei seitlichen Ausbuchtungen versehen.

Vor der Einmündungsstelle des Wolff'schen Ganges in die Cloake zweigt sich ein vor dem ersteren liegender selbständiger Blinds ack ab. Derselbe besitzt ein grösseres Caliber als der Wolff'sche Gang. und hat, da er in 3-4 Schnitten sichtbar ist, eine Lünge von nur 0,3-0,4 mm. Diesen Blindsack muss man für die Anlage des Nie. renganges halten, der nach den, neuerdings durch Kölliker bestätigten Angaben Kupffer's aus dem untern Ende des Wolff'schen Ganges sich entwickelt.

W. Nagel (Ueber die Entwicklung des Urogenitalsystems des Menschen, Arch. f. mikr. Anat. Bd. 34) beschreibt den Urogenitalapparat zweier, dem zweiten Monat der Schwangerschaft entstammender Embryonen, welche im gehärteten Zustande 12 bezw. $13 \mathrm{~mm}$ massen. Ueber die erste Entwicklung der Urnieren kann er deshalb nichts Neues bringen, weil sie in dem Stadium, welches seine Embryonen boten, bereits bis zur Funktionsfähigkeit ausgebildet waren. Dennoch theile ich seine Beobachtungsresultate hier im Restumé mit, weil sie von Embryo-

1) Sollte wohl heissen "hinteren". 
nen in untadelhaftem Zustande stammen und sich speciell auf das Urogenitalsystem beziehen. - Die Urnieren reichen bis zur untersten Grenze der Lungenanlage. Sie sind überall an ihren freien Flächen mit einem einschichtigen Cylinderepithel bekleidet, dessen Zellen durch ihre Grösse von den niedrigen, cubischen Zellen des Peritonealepithels deutlich abstechen. Besondere Grösse zeigen die Epithelien über demjenigen Theil der Leiste, unter welchem der Wolff'sche Gang verläuft; aus diesem Epithelwulst geht der Müller'sche Gang hervor. Letzterer ist in der obern Hälfte der Urniere, gerade aussen voin Wolff'schen Gange, bereits angelegt. An der Innenseite der Wolff'schen Leiste deutet ein Epithelwulst die Geschlechtsdrüse an. Die Glomeruli liegen alle in dem medialen Theile der Urniere, sind dicht aneinander gereiht und finden sich noch in dem proximalen Ende des Organs. Dieselben messen durchschnittlich 80-112 $\mu$ und zeigen den bekannten Bau : in eine Erweiterung des blinden Endes des Querkanälchens hinein ragt ein mit Epithel bekleideter Gefïsskniiuel. Die Bowman'sche Membran ist theils mit platten Epithelzellen bekleidet, theils mit cubischen, welche sich in nichts von denjenigen der übrigen Kanälchen unterscheiden. Der Uebergang von einem Epithel zum andern ist ein allmählicher. Die Querkanälchen haben einen vielfach gewundenen Verlauf; man unterscheidet weitere und schmälere; ein Unterschied des Epithels ist nicht zu erkennen. Dagegen beschreibt er von Embryonen von 18-23 $\mathrm{mm}$ Länge genau den Unterschied des Epithels in den engern und weitern Abschnitten der Kanallchen. In den engern Abschnitten unterscheidet es sich nicht von demjenigen des Wolff'schen Ganges; in den weitern aber ist es viel grösser, färbt sich schlecht und besitzt vielleicht Cilien, wie sie von Janosik und Nicolas bei Säugethierembryonen beschrieben werden. Die weiten Abschnitte der Kanälchen gehen unmittelbar in die Bowman'sche Kapsel über und gehören zum secretorischen Apparate der Urnieren. Im obersten Theile der Urniere trifft man nur Kanälchen kleineren Kalibers, welche sich erst weiter distalwärts zum Wolf'schen Gang vereinigen. $\mathrm{Ob}$ sie mit der Bauchhöhle in Verbindung stehen (wie er in dem Beitrag zur Lehre von der Herkunft des Fruchtwassers im Arch. f. Gyn. Bd. 35 gemeint hatte) vermag er nicht mit Bestimmtheit zu entscheiden; jedenfalls gehen sie bis dicht an das Oberflächenepithel heran. Der Wolff'sche Gang verliuft an der Aussenseite des Wolff'schen Körpers; im distalen Theile liegt er dem Oberflächenepithel näher, als im proximalen Abschnitte des Organs; er nimmt in regelmässigen Zwischenräumen die Harnkanälchen auf. Die Wolff'schen Körper verjüngen sich distalwärts und gehen in die Plica e urogenitalis über, in deren Spitzen je ein Wolff'scher Gang verläuft. Die Wolff'schen Gänge münden getrennt in den Sinus urogenitalis und zwar nach innen und etwas oberhalb von den Nierengïngen. Der Sinus urogenitalis zeigt hier auf dem Querschnitt halbmondförmige Gestalt und gibt rentralwärts sehr bald die Allantois ab; dann bekommt er ovalen Querschnitt und mündet in den Darm. 
Prof. J a n osi k (Prag) (Zwei junge mensehliche Embryonen. Arch. f. mikr. Anat. Bd. 30) fand bei einem im frischen Zustande $3 \mathrm{~mm}$ langen Embryo vom Urog'enitalsystem : Wolff'schen Gang; einige Bläschen und Zellblastem. Das vorderste Ende des Wolff'schen Körpers liegt da, wo der ductus omphalo-entericus abgeht, Es ist an 3 Schnitten zu sehen: am vordersten bemerkt man eine leichte Verdickung des Pleuroperitonealepithels an umgrenzter Stelle mit Spross zwischen die indifferenten Zellen des Mesoderms; am nächsten Schnitt ist dieselbe deutlicher; am dritten sieht man nur einige abgelöste Zellen im Mesoderm. An den nächsten Schnitten ist davon nichts zu beobachten. Erst am 26. Schnitt erscheint eine kleine Einstülpung des Epithels, welche wieder bis zum 35. Schnitte zu sehen ist. Vor dem vordersten Kanälchen denn um solche handelt es sich - liegt eine Prominenz in die Pleuroperitonealhöhle, welche auf drei Schnitten zu sehen ist, einem äusseren Glomerulus der Vögel ähnlich sieht und vielleicht den Rest ein er Vorniere darstellt. Gleich hinter dem zweiten Kanälchen erscheint der Durchschnitt des Wolff'schen Ganges; er ist von keiner besonderen Grösse, relativ schwächer als bei Kaninchen und hängt mit dem vordern Ende mit demPleuroperitonealepithel zusammen. Die Zellhäufchen bekommen nach hinten zu Lumina durch Einschmelzen der centralen Zellen. Die ganze plica urogenitalis prominirt nur wenig in's Coelom. Das Epithel derselben ist lateral und ventral einschichtig, cubisch ; medial, wo es ins Mesenterium übergeht, mehrschichtig und nicht scharf gegen das unterliegende Gewebe begrenzt. Wo die Bläschen nicht mehr zu sehen sind, liegt distal eine von Strecke zu Strecke mit dem Epithel verbundene Zellmasse; ganz hinten ist sie vom Epithel gelöst.

Der Wolf'sche Gang verlïuft nach hinten ohne Verbindung mit dem Epithel oder den Bliischen; ist viel deutlicher und zcigt stellenweise deutliches Lumen. Hinten endigt er blind, ohne Tendenz, sich mit der Cloake zu verbinden.

Prof. G. Chiarugi (Siena) beschreibt (in Arch. ital. de Biologie, T. XII, fasc. I-II, 1889) einen in Spiritus gehärteten 2,6 mm langen Embryo, den er sonderbarer Weise in 92 Schnitte von $0,035 \mathrm{~mm}$ zerlegt hat. Der Wolff'sche Körper wird gebildet von einem cylindrischen, soliden Zellstrange, welcher in der Mitte des absteigenden Rumpfabschnittes beginnt und bis „zum. Beginn der letzten Krümmung*" reicht. Er liegt aussen vom Segmente des Mittelblattes (Urwirbelplatte) am seitlichen Theile der Rückwand der Bauchhöhle, welche daselbst etwas vortritt. Dieser Vorsprung ist auf der innern Seite durch einen Einschnitt vom Mesenterium getrennt.

H. Fol (Sur l'anat. d'un embr. hum. de la $4 \mathrm{~mm}$ semaine. Compt. rend. d. l'acad. d. sc. à Paris, T. 97, 1883) beschreibt ganz kurz einen in frischem Zustande 5,6 mm langen Embryo, den er in 164 Schnitte von $0,02 \mathrm{~mm}$ zerlegte. Ueber das Genitalsystem bemerkt er nur, dass die Ureteren am ventralen und nicht am dorsalen Rande der Cloake, 
wie man irrthümlicher Weise geglaubt habe, münden. Diese Thatsache erkläre viel leichter die Entwicklung der Blase.

Bei meinen Embryonen sind vom Urogenitalsystem die Urnieren und beim ältern atch die Anlagen der bleibenden Nieren vorhanden. Von den Müller'sehen Gängen fehlt noch jede Andentung.

\section{Die Urnierenleisten.}

Die Urnieren sind in spindelförmigen Gewebswüilsten, den Urnierenleisten, enthalten, welche beiderseits an der Wurzel des Darmgekröses in die Leibeshöhle hereinragen. Sie beginnen oben kammartig, werden nach unten zu höher und breiter, verlieren gegen das Ende hin wieder ein wenig an Umfang und hören ziemlich scharf abgeschnitten auf.

Bei Embryo II erreichen sic den grössten Unfang wenig unterhalb des Ductus omphalo-entericus. Ihre Basis, d. h. die Verbindung:sgerade des Grundes der sie begrenzenden Buchten (s. Fig. 10), misst dort 0,41 mm; ihre Höhe, oder die Senkrechte von ihrem Kamme auf die Basis, beträgt 0,21 mm. Gegen oben hin läuft jede in eine schmale, scharf vortretende Leiste ans, welche nur die Vena cardinalis einschliesst und mit ihr nach vorn zieht. Distalwärts nimmt sie nur ganz wenig ab, um aber dann, nachdem die Querkanälchen aufgehört haben, sehr rasch abzufallen und ganz auszulaufen. Nur der Anfang des Ausführungsganges erhebt noch eine flache Hervorragung; dann entfernt er sich vom Peritonealepithel und verläuft gan\% in der Gewebsmasse der hintern Körperwand eingebettet, ohne dass sein Verlauf durch eine in die Leibeshöhle vorragende Leiste bezeichnet würde.

Die Wolff'schen Leisten sind nicht direct nach vorne, sondern nach vorn und seitlich gerichtet (s. Fig. 8-11), so dass ihre Höhen ungefähr im Centrum des Aortenlumens sich ziemlich genan in einem rechten Winkel schneiden. Daraus folgt von selbst, dass die sie seitlich begrenzenden Einsenkungen aussen viel tiefer sind als innen. Da, wo der Dottergang abgeht und der Darm eine scharfe und hohe Schlinge gegen den Nabel zu bildet, wird die Neigung der Leiste dadurch noch vergrössert, dass zwischen Gekröse und ihr eine Einsenkung kaum angedeutet ist, während die äussere um so tiefer erscheint. Die Leiste ist 
nur am oberen Ende schön abgerundet; sonst zeigt ihr Kamm so starke Abflachung, dass der Querschnitt delselben fast rechteckig erscheint (s. besonders Fig. 9 u. 10).

Die Leiste ist von einer Schichte durchaus gleichmässiger Cylinderzellen von $0,006 \mathrm{~mm}$ bedeckt. An der Basis setzen sich diese Epithelien innen auf das Mesenterium des Darmes fort, während sie aussen in die niedrigen Cylinderzellen der Bauchwand übergehen. Weder am äussern noch am innern Rande ist eine Vergrösserung oder eine doppelte Schichtung von Epithelzellen zu beobachten.

Das Inmere der Leiste besteht aus einem lockeren Bindegewebe mit runden, ovalen bis spindelförmigen Kernen. Es ist von zahlreichen, zum Theil sehr starken Gefässen durchzogen.

Bei Embryo I beginnen die Wolff'schen Leisten relativ weiter unten. Erst von dem Abgang des Nabelganges an treten sie zunächst in der Mitte, nach und nach in der ganzen Breite an der Stelle, welche Mittelplatte heisst, gegen die Leibeshöhle vor. Sie nehmen an Umfang gegen unten hin zu und bilden vom Beginn der Steisskrümmung an walzenartige Wülste, zwischen welche hinein sich von hinten her die ungemein weite Aorta drängt (s. Fig. 12 u. 13). Am untern Ende fallen sie rasch ab und laufen in ganz unbedeutende Vorwölbungen der Mittelplatten aus (s. Fig. 12).

Die sie begrenzenden Rinnen sind ebenfalls auf der äusseren Seite beträchtlich tiefer als innen (s. Fig. 12), so dass auch hier die Wülste nicht direct ventralwärts, sondern nach vorn und aussen schanen. Da, wo sie ihren grössten Umfang erreicht haben, sind ihre Kämme etwas abgeflacht. Ihre Basis misst $0,16 \mathrm{~mm}$, ihre Höhe $0,09 \mathrm{~mm}$.

Der Epithelbelag der Leiste ist ein durchaus gleichmässiger. Am Uebergang auf das Mesenterium wird er zwei- bis dreischichtig und hebt sich nicht scharf gegen die Unterlage ab (s. Fig. 12). Aussen setzt er sich in die niedrigen Epithelien der Bauchwand fort.

Das Innere der Leiste zeigt ein lockeres, blutloses Gewebe mit runden oder ovalen Kernen; einzelne Züge spindelförmiger Kerne sind als Gefässanlagen zu deuten.

Die venae cardinales zeigen bei den beiden Embryonen ausserordentlich verschiedene Grösse. 
Beim ältern ist die Vene ein weites, etwas abgeplattetes Gefäss (s. Eig. 8-11). Ihr Durchschnitt erscheint oval; die eine lange Seite liegt dem Epithel des äusseren Umfanges der Wolff'schen Leiste an, während die andere direct an den ersten Bogen der Urnierenkanälchen stösst. Proximalwärts nimmt die v. cardinalis fast die ganze Wolff'sche Leiste ein; sie drängt die übrigen Gebilde der Urniere ganz nach innen zu und tritt ventralwärts über sie hervor ${ }^{1}$ ). Nach unten zu werden aber die Drïsenbestandtheile allmählich umfangreicher und gewinnen über die Vena das Uebergewicht. Diese wird nach hinten und aussen gedrängt; jedoch schickt sie jedesmal zwischen den Einmündungsstellen der Kanälchen eine Ausbuchtung nach vorn (s. Fig. 8); mit andern Worten: die Querkanälchen bedingen dort, wo sie itber die v. cardinalis hinweg zum Wolff'schen Gang verlanfen, Einziehungen.

Die Aeste, welche von den Glomeruli kommen, entspringen der inneren Seite; doch treten sie bald mehr ventral, bald mehr dorsalwärts von der Wand ab. Oftmals zeigen diese Aeste vor der Einmündung in die Vene eine sinusartige Erweiterung.

Beim jüngern Embryo sind die venae cardinales noch sehr wenig entwickelt. Mehrmals verschwindet ihr Lumen vollständig und wo es am weitesten ist, da beträgt es $0,013 \mathrm{~mm}$ auf $0,026 \mathrm{~mm}$; ist also auch abgeplattet. Die Vene liegt am äusseren Rande der Wolff'schen Leiste und ber'ïhrt die Basis derselben (s. Fig. 12). Von ihr aus ziehen im Bogen um die Querkanälchen herum Gefässanlagen nach den Stellen der zukünftigen Glomeruli hin.

\section{Die Urnieren-Gänge.}

Jeder Urnierengang stellt bei Embryo II einen gestreckten, am vorderen äusseren Rande der Wolff'schen Leiste, direct unter dem Epithel verlaufenden Kanal dar. Sein Querschnitt (s. Fig. 8-11) zeigt ovale Form; eine längere Seite liegt dem Epithel an. Seine Wandung besteht aus einem einschichtigen Kranze $0,006 \mathrm{~mm}$ hoher Cylinderzellen, deren runde Kerne 0,004 mm messen. Er misst im mittleren Verlaufe $0,032 \mathrm{~mm}$ auf $0,020 \mathrm{~mm}$

1) Die Fortsetzung der Wolff'schen Leiste nach vorn wird ja gebildet durch den Wulst, den die v. cardinalis nach der Pleuroperitonealhöhle erhebt. 
in die Dicke. Nach unten zu behält er diese Stärke; während er nach oben hin ein wenig abnimmt. Ja an einzelnen Stellen ist er hier nur durch einen cylindrischen Strang atrophischer Zellen, ohne Lumen, angedeutet. Dies ist der Fall zwischen den Einmitndungen des 6. und 7. Querkanälchens links und zwischen denjenigen des 8 . und 9. rechts. An den Einmündungsstellen dieser Kanälchen selbst wird der Gang wieder normal. Auch oberhalb dieser Stellen zeigt er gute Entwicklung. $\mathrm{Ob}$ hier eine ursprüngliche Segmentirung des Ganges angedeutet sei oder bereits beginnende Rückbildung vorliege, ist wohl nicht mit Sicherheit zu entscheiden. Der Wolff'sche Gang wird von den Kanälchen und Glomeruli um $0,1 \mathrm{~mm}$ ïberragt.

Der Urnierengang verlässt die Drüse auf der Höhe der Steisskrümmung, ungefähr entsprechend dem Ansatze des unteren Extremitätenstummels. Er verlüuft von da an in der hinteren Körperwand, ziemlich genau in der Mitte zwischen sagittaler Mittelebene und seitlicher Oberfläche des Körpers, 0,05 mm vom Peritonealepithel entfernt. Eine deutliche Hervorragung nach der Peritonealhöhle hin bedingt er nur anfänglich eine ganz kurze Strecke weit. Auf dem Wege zur Cloake tritt er ein wenig ventralwärts. Die seitliche Verschiebung ist kaum merkbar, weil er durch die Verschmälerung des untern Körperendes von selbst an die seitliche Wand der sehr breiten Cloake zu liegen kommt.

Nach dem Verlassen des Wolff'schen Körpers zeigt der Gang die gleiche Stärke wie oberhalb. Nach einer Strecke von $0,24 \mathrm{~mm}$ aber nimmt er den Nierengang auf (s. Fig. 2 und Fig. $7^{\mathrm{a}-\mathrm{d}}$ ) und bekommt als Sinus urogenitalis eine Dicke von $0,074 \mathrm{~mm}$ und ein Lumen von $0,047 \mathrm{~mm}$. Diesen Umfang behält er aber bloss $0,08 \mathrm{~mm}$ weit; dann wird er zu einem dickwandigen Kanal von nur 0,054 Durchmesser und 0,016 Lichtung und miindet nach $0,05 \mathrm{~mm}$ in die Cloake ein.

Letztere zeigt an dieser Stelle einen Querschnitt, welcher an das bekannte Bild des flammenden Herzens erinnert (s. Fig. $7^{\mathrm{d}}$ ): ein $0,168 \mathrm{~mm}$ breites Lumen von Herzform trägt oben eine kleinere, $0,064 \mathrm{~mm}$ breite, spitz zulaufende Ausbuchtung. Die Wolff'schen Gänge münden beiderseits auf den abgestumpften Hörnern der herzförmigen Abtheilung, während fast auf gleicher Höhe die Allantois von der ventralen Spitze abgeht (s. Fig. $7^{\mathrm{e}}$ ). Die Wolff'schen Gänge sind es zum Theil, welche diese seitlichen Ausbuchtungen so bedeu- 
tend verstärken; denn sobald sie sich vollständig mit der Cloake vereinigt haben, verschwinden diese hornförmigen Ausbuchtungen allmählich; die beiden Abtheilungen verschmelzen ganz mit einander, so dass nun der Durchschnitt der Cloake die Form eines stehenden Ovals bekommt, an welchem immerhin die Einmündungsstellen der Wolff'schen Gänge noch eine Strecke weit als leichte seitliche Ausbauschungen zu erkennen sind (s. Fig. $7^{\mathbf{f}}$ ).

Proximalwärts trennt sich die Cloake vom nächsten Schnitte (c) an in die schon in Fig. $d$ angedeutete obere und untere $A b$ theilung. Die obere ist kleiner, zeigt die Form eines gleichschenkligen Dreiecks mit der Spitze dorsalwärts und stellt den erweiterten Darm vor. Er verengt sich von dia an rasch; nach $0,08 \mathrm{~mm}$ ist seine Lichtung kaum noch wahrnehmbar. Die untere Abtheilung schliesst nach 0,08 $\mathrm{mm}$ mit abgerundetem Ende ganz ab. Es stellt diesclbe also einen proximalwärts gerichteten Blindsack der Cloake dar (s. Fig. 2).

Der Nierengang, ungefähr gleich stark wie der Wolff' sche Gang, jedoch von einem breiteu Hofe dicht gedrängter Zellen umgeben, tritt ans der hintern Wand der letzteren und divergirt nach hinten. Er läuft $0,04 \mathrm{~mm}$ weit in einen dicht gefügten kammförmigen Zellhaufen hinein, dessen abgerundetes Ende

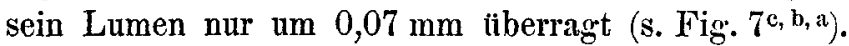

Das obere Ende des Wolff'schen Ganges entfernt sich etwas vom Peritonealepithel, indem es nach innen zu verläuft, um direct in das erste Querkanälchen überzugehen.

Die ganze Länge des Wolff'schen Ganges beträgt 3,73 mm; davon fallen auf seinen Verlanf längs der Urmiere $3,32 \mathrm{~mm}$ und auf den Ausführungsgang im engeren Sinn 0,41 mm. Das Verhältniss der gekrümmten Längsachse des Körpers zur Länge des Wolff'schen Ganges beträgt demnach 13,33: 3,73=3,ō7.

Bei Embryo I habe ich den Wolff'schen Gang zuerst und am deutlichsten erkannt in jenen Sehnitten, wo er der Länge nach getroffen ist, also auf der Höhe der Steisskrïmmung. Ich gehe deshalb auch bei der Schilderung von jener Abtheilung aus.

Fig. 3 auf Taf. V zeigt aus einem dieser Schnitte die Mitte der rechten Seite. Der Schnitt liegt so weit distal, dass von der Leibeshöhle nur noch ein schmaler Spalt wahrzunehmen ist. Vom Darmrohr kann selbstredend nichts mehr getroffen sein. Dagesen figurirt in dem Schnitte nach links hin die Aorta so ziemlich mit ihrem gröss- 
ten Lumen natürlich auch der Länge nach aufgeschnitten. Sie kennzeichnet sich dureh die in ihr enthaltenen Blutkörperchen. Zwischen dem spaltförmigen Ausläufer der Leibeshöhle und dem Lumen der Aorta liegt der Wolff"sche Körper, welcher demnach gerade an der Seite der verhältnissmässig enorm weiten Aorta herunterläuft. $\mathrm{Er}$ besteht aus einer Reihe von Zellhäufchen, welche im Centrum ein mehr oder weniger deutliches Lumen erkennen lassen. Aussen an diesen Zellhäufchen zieht sich der Wolff'sche Gang hin. Er ist aus zwei einander berührenden Reihen von Zellen aufgebaut, zeigt demnach keine Lichtung.

Im Vergleich zu den Zellen, welche die Anlagen der Querkanälchen darstellen, erscheinen die Wandungszellen des Wolffschen Ganges deutlich abgeplattet. Der Unterschied ist im Priaparate selbst so in die Augen springend, dass man unwillkürlich verschiedene Abstammung der Zellen vermuthet und bereits dadurch die getrennte Entstehung der Querkanälchen und des Ausführungskanals wahrscheinlich wird.

Verfolgen wir den Wolff'schen Gang nach unten, so finden wir ihn 10 Schnitte weiter schief durchschnitten als ein länglichovales Zellhäufchen, wclches nach einem Einschnitte der Körperoberfläche hinweist. Dieser Einschnitt senkt sich zwischen Urwirbelund Mittelplatte linein. Nach abermals 5 Schnitten ist die Anlage des Wolff'schen Ganges mit jenem Einschnitte in Verbindung getreten. Fig. 4 zeigt dies. Es stellt mithin jetzt die Anlage des $\mathrm{Ur}^{-}$ nierenganges einfach eine zwischen Urwirbel- und Vittelplatte hereinragende Einstülpung des Ectoderms dar. Die Zellen des Ectoderms und dieser Anlage unterscheiden sich denn auch in Bezug auf Grösse und Gestalt fast nicht von einander.

29 Sehnitte hindurch lässt sich diese Einsenkung des Ectoderms gegen das Schwanzende hin verfolgen. Zum letzten Male sehen wir sie rechterseits so wie sie Fig. 5 zeigt auf der Höhe des untern Extremitätenstummels, 3 Schnitte weiter bekommen wir das Bild, welches Fig. 6 darstellt. Die Einstülpung hat sich vom Ectoderm abgelöst und legt sich der Wand des spaltförmigen Darmes und zwar mehr ventralwärts an (der Schnitt ist auf der linken Seite des Embryo etwas voran). Zugleich erscheinen die Anlagen der Wolff'schen Gänge nicht mehr als einschichtige Zellstränge, sondern als Gänge mit deutlichen Lumina (s. besonders links) und verdickten Wandungen. Die zwischenliegenden Schnitte zeigen, dass diese Disloca- 
tion allmählich geschieht, die Anlage der Gänge also in leichten Bogen der Bauchfläche und der Sagittalebene sich nähern. Nach abermals 4 'Schnitten schliessen die Gänge mit abgerundeten Enden ab. Eine Verbindung ihrer Zellen mit denjenigen der Darmwand findet nicht statt. Die Wolff'schen Gä̀ge münden also noch nicht in den Darm ein.

Die Cloake zeigt, wie auf der Fig. 6 zu sehen, eine dorsalwärts breite, abgerundete, nach unten spaltartig zulaufende Lichtung. Von der Nierenanlage ist nichts zu beobachten; wenn man sie nicht in diesem kenlenartig verdickten Ende des Wolff'schen Ganges suchen will.

Gegen das Kopfende zu stellt der Wolff'sche Gang einen seitlich comprimirten, stellenweise schwierig wahrnehmbaren Kanal dar, wie dies auf Fig. $12 \mathrm{zll}$ sehen ist. Seine Wandnngen bestehen aus einer Schichte niedriger Cylinderepithelien und schliessen ein spaltförmiges, uiberall mehr oder weniger deutlich wahrnehmbares Lumen ein. Dieses Lumen ist wohl entstanden durel Auseinandertreten der anfänglich sich beribrenden Wandungszellen. Eine andere Entstehungsart kann man sich bei dem von Anfang an ans einei einzigen Zellschichte bestehenden Wandung nicht vorstellen.

$0,13 \mathrm{~mm}$ vor dem obern Ende, unmittelhar nach der Einmündung des zweitobersten Querkanälchens nimmt der Gang plötzlich andere Beschaffenheit an. Znerst verdickt sich seine immere Wand zur Aufnahme des letzten, etwas verkümmerten Querkanälchens; dann werden auch die Zellen der übrigen Wandung höher und zum Theil zweischichtig, so wie es Fig. 13 zeigt. Er stellt jetzt einen dickwandigen Cylinder mit kleinem rundlichen, centralen Lumen dar und verläuft nach Einmündung des letzten Querkanälchens noch $0,07 \mathrm{~mm}$ weit nach oben. Es wird hier allmählich dünner, verliert $0,04 \mathrm{~mm}$ vor dem Ende seine Lichtung und endigt spitz zulaufend. In diesem obersten Verlaufe rïckt er immer mehr der Mitte der sich abflachenden Wolff'schen Leiste zu, behält dabei seine peripherische Lage, unmittelbar unter dem Epithel, ohne jedoch mit demselben in Verbindung zu treten.

Vielleicht könnten wir dieses oberste Stïck, statt es dem Wolff'schen Gange beizurechnen, mit eben so viel Berechtigung als oberstes Querkanälchen, welches direct ins proximale Ende des Wolf'schen Ganges einmündet, auffassen. Der plötzliche 
Wechsel im Bau des Ganges wäre dadurch leichter verständlich; auch hätten wir anf diese Art die Analogie mit dem Verhalten bei unserem älteren Embryo sowie bei den Embryonen von anderen Autoren z. B. N a gel (Ueber die Entwicklung des Urogenitalsystems des Menschen. Arch. für mikrosk. Anat. Bd. XXXIV) hergestellt. Diesel Auffassung widerspricht nur der Umstand, dass der Gang seinen Bau ïndert schon vor der Aufnahme des letzten Querkanälchens, und dass er spitz zuläuft, während bei Embryo II das oberste Querkanälchen ein richtiges Malpighi'sches Körperchen träg't.

Ob nun aber die eine oder die andere Auffassung der Wirklichkeit entspreche, so können wir das Ganze als einen fortlaufenden Gang betrachten. Die verschiedene Beschaffenheit seiner ununterbrochen in einander ubbergehenden Theilstücke jedoch deutet auf verschiedene Abstammung derselben. Es wird sich weiter unten zeigen lassen, dass die Querkanälchen der Urniere ursprïnglich mit dem Peritonealepithel in Verbindung. standen. Auch wenn wir das oberste Ende des Wolff'schen Ganges nicht als erstes Querkanälchen gelten lassen, so werden wir wegen der übereinstimmenden Zellen nicht anstehen, gleiche Abstammung anzunehmen.

Daraus ergibt sich fiir die Genese des Wolff'schen Ganges, dass sein proximaler Theil aus dem Mesoderm hervorgeht und anfäglich mit dem Pleuroperitoneal-Epithel in Verbindung steht, während sein distaler Theil mit dem Ectoderm sich verbindet. Er stellt also ursprünglich eine röhrenartige Verbindung der Leibeshöhle mit der Oberfläche des Körpers dar, deren Enden erst durch das Längswachsthum des Individuums auseinanderger ì ckt $\sin d^{1}$ ).

Die ganze Länge des Wolff'schen Ganges bei Embryo I beträgt $1,87 \mathrm{~mm}$; davon fallen $1,48 \mathrm{~mm}$ anf den Verlauf in der Wolff'schen Leiste; $0,33 \mathrm{~mm}$ weit zieht er sich am Ectoderm hin und 0,06 mm braucht er, um an den Darm heranzutreten. Das Verhältniss der gekrümmten, idealen Längsachse des Körpers zur Länge des Wolffschen Ganges ist demnach 6,04:1,87 $=3,24$.

Ueber die Entstehungsart des Wolff'schen Ganges bei Thieren gehen die Ansichten der Forscher noch auseinander. Die Einen

1) S. Hertwig, Lehrb. der Entwicklungssgeschichte. 
leiten ihn vom Mesoderm, Andere vom Ectoderm ab. Von den Ersteren lässt ihn wiederum ein Theil durch Ausstïlpung der Peritonealhöhle entstehen, während die Uebrigen einen anfänglich soliden aus der Mittelplatte herauswachsenden Zellstrang als Anlage desselben betrachten.

So fanden Götte und Rosenber ${ }^{1}{ }^{1}$ bei Batrachiern und Fischen, dass der Wolff'sche Gang als Ausstülpung der Peritonealhöhle entstehe. C. K. Hoffmann (Zur Entwicklungsgesch. d. Urogenitalorgane bei d. Anamnia; Ztschr. f. wiss. Zool. Bd. 44, 1886) und W. Romiti ${ }^{2}$ ) ans Livorno bestätigen diese Ansicht. $\mathrm{K}$ ow al esky ${ }^{3}$ ) berichtet das Namliche anch rom Hühnerembryo. Dansky und Kostenitseh4) erkliiren ihn nach Untersuchungen am Hühnchen als Ausstülpung der Spalte, welche die Pleuroperitonealhöhle mit der Urwirbelhöhle verbindet.

Die meisten Untersucher kamen zu dem Resultate, dass der Wolff'sche Gang aus der Zellmasse der Mittelplatte als solide Anlage hervorwuchere. Bereits Remak5) sagt, dass er aus ,dem innern Rande der Seitenplatten " als anfangss solide Zellmasse, die spitter hohl werde, entstehe. Walde yer ${ }^{6}$ ) litsst ihn aus einem soliden Strang, der in Verbindung mit den Zellen der Mittelplatte steht, hervorgehen. Das Lumen bilde sich durch Abplattung und Zusammenrollen. Mit ihm stimmen überein Forster und Balfour ${ }^{7}$ ). Nach Max Braun ${ }^{8}$ ) bildet die Anlage des Wolff'schen Ganges bei den Reptilien eine Zellmasse, welche nach dem Ectoderm hin prominirt, den Seitenplatten anliegt und mit ihren Zellen in Verbindung steht, ohne mit der Leibeshöhle zusammenzuhängen. $J_{\text {ano }} \operatorname{sik}^{9}$ ) sagt nach Untersuchungen am Hühnerembryo : der Wolff'sche Gang entsteht als solide Verdickung des dorsalen Theiles der Mittelplatten. Eg Ii ${ }^{10}$ ) vermuthet, dass beim Kaninchen

1) Diss. Dorpat 1867.

2) Ueber den Bau und die Entwicklung des Fierstockes und des Wolff'schen Ganges (aus d. anat. Instit: d. Univers. Strassburg; Arch. f. mikrosk. Anat. Bd. 10. 1874).

3) Die Entw. d. Anfänge d. Urogenitalsystems b. Hühnerembryonen (Warschau 1875).

4) Ueber die Entwicklung der Keimblase und des Wolff'schen Ganges im Hühnerei (Mém. de l'acad. d. se. d. St. Petersbourg. Sér. III. T. XXVII, 1880).

5) Untersuchung. über d. Entwickl. d. Wirbelthiere (Berlin 1855).

6) Eierstock und Ei (Leipzig 1870).

7) Grundzüge der Entwicklungsgeschichte der Thiere (1876).

8) Das Urogenitalsystem der einheimischen Reptilien (Arb. aus d. zool.-zoot. Inst. in Würzburg, IV. Bd. 1877/78.)

9) Histolog.-embryolog. Untersuch. über das Urogenitalsystem (Sitzber. d. k. k. Acad. d. Wissensch. in Wien. Bd. XCI, III. Abth. 1885).

10) Zur Entwicklung d. Urogenitalsystems beim Kaninchen (Diss. Basel 1876). 
der die Anlage des Wolf'schen Ganges darstellende Zellstrang am neunten Tage isolirt zwischen Urwirbel und oberer Seitenplatte wachse. Gasser ${ }^{1}$ ) und nach ihm Siemerling ${ }^{2}$ ) sehen als Anlage des Wolff'schen Ganges eine gegen das Ectoderm wucherncle solide Verdickung: der Mittelplatten an. Bornhaupt ${ }^{3}$ ) sagt : am Ende des zweiten Brüttages sieht man beim Hühnchen den Wolff'schen Gang' als soliden Streifen, welcher anfänglich dem den Wolff'schen Körper darstellenden Streifen der Mittelplatte autliegt. Aehnlich lisst Sedgwik ${ }^{4}$ ) den Wolff'schen Gang beim Hühnchen gerade wie die Urnierenkanälchen aus der intermediairen Zellmasse hervorgehen. Er entstehe als Auswuchs dieser Zellmasse in der Gegend vom 7.-11. Urwirbel, wachse von hier aus frei nach hinten und bleibe nur eine kurze Strecke mit der intermediären Zellmasse in Verbindung. Ebenso ist Rensoll ${ }^{5}$ ) der Ansicht, dass der Wolff'sche Gang mit den Urnierenkanälchen aus der niimlichen Anlage hervorgehe. Die vordere Abtheilung bilde sich dadurch, dass die durch Einstülpung des Pleuroperitonalepithels entstandenen Urnierenkanïlchen an ihren inneren Enden seitliche Fortsätze treiben, welche sich miteinander zu einem Kanale verbinden. Vom 11. Urwirbel an stülpe sich eine continuirliche Zellmasse, „la masse intermédiaire", ein, aus welcher später die Urnierenkanälchen und auf der äussern Seite der Wolff'sche Gang' sich herausdifferenzire. Dursy ${ }^{6}$ ) leitet den Wolff'schen Gang vom äussern Theil der Urwirbelplatte ab. Auch $\mathrm{H}_{\text {is }}$ ) liisst ihn als soliden, anfangs segmentirten Zellstrang entstehen, dessen Zellen aus den iussern Abschnitten der Urwirbelkerne stammen. Er sei zur Zeit der Abgliederung der Urwirbel von den Seitenplatten an der Aussenseite der ersteren zu sehen. Von den Urwirbelkernen trete ein Theil der Zellen durch die Lücke, welche zwischen dem Stammtheil und dem Parietaltheil der animalen Muskelplatte entsteht und die austretenden Massen sammeln sich zu einem neben der äussern Urwirbelwand herlaufenden Lüingsstrang.

Der niimliche Forscher hatte jedoch in seinen Beobachtungen über den Bau des Säugethier - Eierstockes die Ansicht vertreten, dass der Wolff'sche Gang vom Ectoderm abstamme. Er fand nämlich bei

1) Entstehung des Wolff'schen Ganges bei Embryonen von Hühnchen und Gänsen (Arch. f. mikrosk. Anat. Bd. 14).

2) Beitrag z. Embryologie d. Excretionsorgane des Vogels (Diss. Marburg 1882).

3) Untersuch. iiber die Entwicklung des Urogenitalsystems beim Hühnchen (Diss. Dorpat 1867).

4) On the early developp. of the ant. part of the Wolff. duct and body in the chicken.

5) Recherches sur le rein céphalique et le corps de Wolff chez les oiseaux et les mammifëres (Arch. f. mikrosk. Anat. Bd. 22, 1883).

6) Zeitschr. f. ration. Medic. 1865 .

7) Unters. über die erste Anlage des Wirbelthierleibes. Die erste Entw. des Hühnchens im Ei (Leipzig 1868). 
Hühnerembryonen regelmässig am hintern Leibesende eine Einstülpung des Ectoderm, genau da, wo Urwirbel- und Seitenplatten sich von einander abgrenzen und bald darauf der Wolft'sche Gang dicht unter der Hornplatte erscheint und hielt dieselbe für die Anlage des Wollf'schen und des Müller'schen Ganges. In seinen drei Jahre später erscheinenden Untersuchungen über die erste Anlage des Wirbelthierleibes widerruft er diese Ansieht und vertritt die oben angeführte. Unterdessen hatte aber die Lehre von der Entstehung des Wolff'schen Ganges aus dem Ectoderm Aufsehen erregt und Bestaitigung erfahren durch Hensen ${ }^{1}$ ) und bald darauf wies auch Graf Spee ${ }^{2}$ ) darauf hin, dass der Urnierengang als eine Verdickung des Ectoderm oberhalb des Grenzstranges (horizontaler Theil der Mittelplatte) entstehe, welche sich nachtrïglich mit dem Grenzstrange verbinde und vom Ectoderm löse.

Diese auseinanderweichenden Ansichten über die Entstehung des Wolff'schen Ganges, welche ihn bald rom Mesoderm, bald rom Ectoderm ableiteten, hat Hertwig ${ }^{3}$ ) in seinem Lehrbuch der Entwicklungsgeschichte in Einklang zu bringen verstanden. Er fasst die Anlage des Wolff'schen Ganges als kurze röhrenartige Verbindung der Leibeshöhle mit der Oberfläche des Körpers auf; der vorderste Theil dieses Ausführungsganges entstehe aus einer rinnenförmigen Ausbuchtung oder aus einer leistenförmigen Verdickung des parietalen Mittelblattes, löse sich hinten von diesem seinem Mutterboden ab, verschmelze mit dem dicht anliegenden äussern Keimblatt und wachse an diesem nach hinten aus, bis er in die Cloake ausmünde. Diese, die Resultate der maassgebendsten Forsehungen zusammenfassende Anschauung wird durch die Untersuchung meines Embryo I in vollstem Maasse bestätigt.

\section{Die Urnierenkanälchen und Malpighi’schen Körperchen.}

Bei Embryo II zeigen die Urnierenkanälchen schon weit vorgeschrittene Entwickelung. Wir zählen beiderseits ihrer 35, welche sämmtlich auf der innern Seite des Wolff'schen Ganges einmünden. Die Mündungsstellen stehen nicht in gleichmässigen Abständen von einander. Die Intervalle sind z. B., von oben beginnend, auf der linken Seite 12, 4, 12, 13, 9, 12, 12, 7, 10, $8,8,13,10,12,8,10,11$ hundertstel Millimeter u. s. f. Am

1) Embryolog. Mittheilung (Arch. f. mikrosk. Anat. Bd. 3).

2) Ueber directe Betheiligung des Ectoderms an der Bildung der Urnierenanlage, des Meerschweinchens (Arch. f. Anat. u. Entwicklungsgeschichte 1884).

3) Lehrb. d. Entwicklungsgesch. des Menschen und der Wirbelthiere (Jena 1888). 
untern Ende rücken sie einander bis auf 0,03 nüher. Die durchschnittliche Dichtigkeit ist auf der linken Seite etwas grösser als anf der rechten. Während dort eine Einmündung auf $0,088 \mathrm{~mm}$ kommt, fällt hier erst eine auf $0,091 \mathrm{~mm}$.

Jedes Kanälchen macht 3 typische Windungen. Vom Wolff'schen Gange aus schlängelt es sich zunächst um die vena cardinalis, welche an dieser Stelle sich etwas zurückzieht, herum und verläuft längs ihrer innern Wand gegen die Aorta hin ins Innere dei Wolff'schen Leiste. Nachdem es die Basis derselben beinahe erreicht hat, schlag.t es sich in scharfem Bogen um und verläuft, nach innen von dieser ersten Windung, wieder der Oberfläche zu. Noch ehe es aber das Epithel völlig erreicht hat, wendet es sich abermals in scharfem Bogen dem Innern der Leiste zu, um sofort in die Malpighi'sche Kapsel uberzugehen.

Die Excursionen der Windungen sind im obern Theil der Urniere am stärksten; nach unten zu werden sie etwas kürzer; am unteren Ende ist namentlich die Mittelwindung stark verkürrt, so dass sie das Oberflächenepithel bei weitem nicht mèr erreicht und nur als ganz kurzes Verbindungsstuick zwischen erster Windung und Malpighi'scher Kapsel erscheint. $\mathrm{Zu}$ oberst sind die Schenkel der 3 Windungen sehr nahe zusammengedrängt. Die obersten 3 Kanälchen erscheinen im Ganzen etwas atrophisch.

Die Windungen liegen im Grossen und Ganzen in einer zur Körperachse senkrechten Ebene, jedoch wird man nie das Lumen des ganzen Kanälchens olne Unterbrechung in einem Sclunitt von weniger als $0,05 \mathrm{~mm}$ Dicke bekommen. Denn es macht atch leichte Excursionen nach oben und unten. Eine Regelmässigkeit ist in diesen Krümmungen nicht zn erkennen. So bekomme icb z. B. an einer Stelle, wo links und rechts ein Harnkanälchen sich auf die gleichen 8 Schnitte vertheilt, mit Beriicksichtigung jedes zweiten Schnittes folgende Reihenfolge:

$$
\text { links }
$$

Uebergang der ersten Windung in die zweite, erste Windung ganz, zweite zur Hälfte, erste Windung weg, zweite ganz, Uebergang in die Kapsel allein noch vorhanden; rechts innere Hälfte der zweiten Windung, zweite Windung und Uebergang in Kapsel, 
inneres Stuck der ersten Windung, erste Windung ganz.

Noch andere Varianten sind zu beobachten, sodass selten ein Kanälchen dem andern in seinem ganzen Verlauf vollkommen ähnlich ist. - Jedoch kommt es in meinen Präparaten nicht vor, dass die benachbarten Kanälchen in einander greifen oder sich gegenseitig in ihrem Verlaufe beeinflussen.

Die zweite Windung ist bei allen Kanälchen spindelförmig aufgetrieben. Während die erste Wintung eine Dicke von $0,020 \mathrm{~mm}$ zeigt, erreicht die zweite in ihrer Mitte eine solche von $0,035 \mathrm{~mm}$. Am Uebergang in die Kapsel tritt wieder Verengerung ein, so dass der Umfang nur wenig beträchtlicher ist, als an der ersten Windung.

Der Verdickung des Kanälchens in der zweiten Windung entspricht im obern Drittel der Urniere eine Ausweitung der Lichtung (s. Fig. 8), während weiter unten die Lichtung fast die gleiche bleibt, die Wandung des Kanälchens aber beträchtlich dicker wird (s. Fig. 10). Das Lumen der ersten Windung ist $0,006 \mathrm{~mm}$; dasjenige der zweiten beträgt im obern Drittel $0,018 \mathrm{~mm}$, also das 3fache. Die Kanalwand besteht aus einer einfachen Schicht $0,006 \mathrm{~mm}$ hoher Cylinderzellen. Weiter unten zeigt die spindelförmig verdickte zweite Windung eine Wandung mit doppelter Lage von Cylinderzellen. Die Zellen haben in diesem mittleren Abschnitte durchaus gleiche Grösse wie in den übrigen ${ }^{1}$ ).

Das Ende jedes Kanälchens erweitert sich in der dritten Windung zu einer Malpighi'schen Kapsel. Diese besitzt ovale Form; ihre Längsachse liegt in der nämlichen Ebene wie die erste und zweite Windung und verläuft auch annühernd mit ihnen parallel.

In das Innere dieser Kapsel hinein drängt sich von der dorsal- und auswärts gerichteten Längswand her ein Glomerulus. Am ausgebildeten Malpighi'schen Körperchen scheint es, als ob er diese Wand ins Innere eingestulpt und zu seinem Ueber-

1) Später werden sie (wie zuerst Waldeyer beim Hühnchen, dann v. Mihalkovicz am Säugethierembryo und Nagel an menschlichen Embryonen von $18 \mathrm{~mm}$ an nachgewiesen hat) grösser als die Epithelien des übrigen Harnkanälchens und besorgen danm nach der Ansicht der Forscher die eigentliche Secretion. 
zug gemacht habe, hernach aber im Innern noch weiter gewachsen sei. Deshalb ist die Eintrittsstelle hilusartig verengt; deshalb zeigt der Glomerulus auch einen Belag von Epithelzellen, wie sie die Wandung desHarnkanälchens aufbauen. Diese Belagizellen setzen sich direct in die nicht eingestuilpte Wand der Kapsel fort; während sie aber ihre ursprïngliche Grösse und Gestalt beibehalten, werden die Zellen der übrigen Wand, also der Bowman'schen Membran, in flache Plattenepithelien umgestaltet. Diese Umgestaltung beginnt am Endpol der Kapsel; denn dort ist sie stets am weitesten vorgeschritten, so dass die Zellen auf dem Durchschnitte oftmals nur ganz zarten Bindegewebsfasern mit kaum wahrnehmbarem Kerne ähnlich sehen, während vielleicht am Anfangspole noch abgeflachte Cylinderzellen die Wand bilden.

Nach der ungleichen Entwickelung der Malpighi'schen Körperchen können wir indessen 4 Abschnitte der Urniere unterscheiden. Der oberste, ca. 1,40 mm lange, kennzeichnet sich durch gerärmige, bis auf 0,14 lange and 0,10 breite Kapseln, deren Wandungen aus ganz diinnen Platten aufgebaut sind und deren Inneres durch den ans mehreren Gefüssschlingen bestehenden Glomerulus bei weitem nicht ausgefüllt wird (s. Fig. 8). Der zweite, ca. 0,30 mm lange Abschnitt zeigt Kapseln von ähnlicher Weite und gleichem Bau, die aber durch einen aus vielen Gefässschlingen bestehenden Glomerulus fast vollständig ausgefüllt werden. In einigen ist der Glomerulus durch ein von der Wand der Kapsel ausgehendes Septum in zwei Abtheilungen geschieden. Wahrscheinlich vollzieht sich hier eine fortschreitende Spaltung des Glomerulus und der Kapsel. Im 3. ca. 0,55 langen Abschnitte ist die Kapsel rundlicher und etwas kleiner; ihre Wandungszellen sind ein wenig höher. Der Glomerulus besteht aus ein em einzigen, die Kapsel ausfüllenden Säckchen, dessen Wandung, gerade wie diejenige der Kapsel, abgeplattete Cylinderzellen zeigt und dessen Inneres mit Blutkörperchen angefuillt ist (s. Fig. 9 u. 10).

Im vierten Abschnitte, welcher ca. $0,32 \mathrm{~mm}$ lang ist, feblen noch bluthaltige Glomeruli. Die Kapsel besitzt eine Grösse von ca. $0,08 \mathrm{~mm}$; ihr Lumen ist klein; ihre Wandungen also um so dicker; diejenige, welche zur Bowman'schen Membran wird, ist dünner als die gegeniiberliegende, welche den zukïnftigen Glomerulus in sich birgt (s. Fig. 11).

Zum Hilus jedes Malpighi'schen Körperchens tritt ein Ge- 
fässzweig aus der Aorta; ebenso eine Vene von der v. cardinalis. Die Vene ist stets etwas weiter als die Arterie. Sowohl die eine wie die andere zeigen öfters sinusartige Erweiterungen in der Nachbarschät des Malpighi'schen Körperchens. Es kommt vor, dass ein Gefässzweig zwei Glomeruli dient; die Regel aber ist, dass jeder Glomerulus seine directe Gefässverbindung von der Aorta und nach der v. cardinalis hin besitzt.

Bei Embryo I stehen die Querkanälchen und Malpighi'schen Körperchen in ihrer Ausbildung noch weit zurück. Doch gelingt es, in der oberen Hälfte der Urniere ihre zukünftige Entwicklung zu erkennen und die einzelnen Theile ihrer Anlage zu clenten.

Mit Bestimmtheit kann man die Einmündungen der obersten 14 Kanälchen in den Wolff'schen Gang beiderseits verfolgen. Die Abstände sind kleiner als bei Embryo II, und anch nicht ganz regelmässig; sie betragen von oben beginnend $4,6,3,3,3,5$, $3,5,5,4,3,2,2,2$ hundertstel Millimeter; im Mittel $0,038 \mathrm{~mm}$ auf der rechten und $0,035 \mathrm{~mm}$ auf der linken Seite; nach unten zu rücken sie näher auf einander.

Am weitesten ist in der Entwickelung dieser 14 obersten Kanälchen die erste Windung, der Ansfïhrungsgang, vorgeschritten. Auf Fig. 12 sieht man aber auch die zweite Windung ziemlich vollständig; indessen zeigt dieselbe doch nirgends eine Ausbildung, wie bei Embryo II; sie steht in der Entwicklung hinter der ersten Windung zurück; meistens bildet sie nur ein kurzes Verbindungsstïck von der Umschlagstelle der ersten Windung zur Malpighi'schen Kapsel.

Bei einem Vergleich der Windungen mit denjenigen bei Embryo II fällt noch auf, dass sie hier fast genan horizontal verlaufen, während sie beim ältern Embryo durch das starke Wachsthum der Vena cardinalis mehr in sagittale Richtung gedrängt werden.

An der Anlage des Malpighi'schen Körperehens ist die Kapsel deutlich zu erkennen, der Glomerulus nur angedeutet. Die Kapsel stellt einen halbmondförmigen Hanfen von grossen Cylinderzellen mit schönem Kerne dar. Seine Längsachse verläuft quer durch die Wolff'sche Leiste; der ventrale Umfang, scharf' begrenzt und stärker gewölbt, liegt dem Peritonealepithel fast an. Der dorsale Umfang erscheint abgeflacht und oft nicht scharf begrenzt, so dass seine Elemente diffns in die Umgebung übergehen. Das Lumen der Kapsel- 
anlage ist, entsprechend der Form des Ganzen, halbmondförmig; gegen später noch sehr klein und liegt etwas excentrisch, so dass die ventralwärts gerichtete, gewölbte Wandung merklich dünner ist, als die gegenüberliegende (s. Fig. 12).

An Hand der von Embryo II gewonnenen Bilder lässt sich die weitere Entwickelung des Nalpighi'schen Körperchens wie folgt schildern. Die dorsale, verdickte Wand bildet die Grundlage für den Glomerulus. Sie wuchert gegen das Innere vor; dadurch wird das Lumen lang ausgezogen und noch stärker gevölbt, so dass es die Form einer schmalen Mondsichel bekommt; die ventrale Wand muss sich dabei auch stärker ausbauchen und zugleich delnen. Die sie aufbauenden Zellen ordnen sich in eine Reihe und werden stark abgeplattet; sie stellen die Bowmansche Membran dar.

An die Zellanhäufung in der dorsalen Wand der primitiven Kapsel treten Blutgefüsse heran. Durch Zerfall der centralen Zellen bilden sich eine oder mehrere Lichtungen; die Blutgefïsse treten mit diesen in Verbindung und ergiessen ihr Blut direct in sie hinein. Durch fortschreitendes Wachsthum dieses Glomerulus im Innern der Kapsel bildet sich an der Eintrittsstelle der Blutgefässe eine Art Hilus. Anhaltspunkte für eine Blutbildung in den Glomeruli, wie sie v. Mihalkovic $z^{1}$ ) wegen der relativen Grösse bei jungen Sängethierembryonen annimmt, kann ich durchaus nicht finden.

Für die Frage nach der Abstammung der Querkanälchen dürfen in dem schon zu weit vorgerïckten Entwicklungsstadium des Embryo II keine Anhaltspunkte gesucht werden. Dagegen giebt uns die Nachforschung beim jüngeren Embryo sehr werthvolle Anfklärungen.

Auf Figur 12 sehen wir ganz deutlich, wie die Epithelbedeckung auf der äussern Seite der Wolff'schen Leiste ins Innere hereintritt und direct in die Wandung der primitiven Kapsel übergeht. Diese steht also in Zusammenhang mit dem Peritonealepithel. Letzteres erscheint an dieser Stelle unterbrochen; die Continnität ist jedoch im Begriffe, durch von der ventralen Seite her vorgeschobene Zellen sich wieder

1) Unters. ïber (l. Entwickl. d. Harn- u. Geschlechtsapparates d. Amnioten (Intern. Monatsschrift t. Anat. u. Hist. Bd. II, 1885̄). 
herzustellen. Ein ganz ähnliches Bild bietet Figur 13. Diese Bilder sind nun gewiss nicht auf die Weise entstanden, dass das bereits ausgebildete Peritonealepithel sich eingestülpt hat, so dass durch diese Einstulpung die Anlage des Querkanälchens nit Lumen sich gebildet hätte; gerade so wenig wie die eine Wand der Malpighi'schen Kapsel erst nach ihrer vollkommenen Ausbildung vom Glomerulus eingestïlpt worden ist.

Um vielmehr diese Bilder richtig verstehen za lernen, müssen wir die allerjüngsten Entwicklungstadien aufsuchen und diese finden sich am nntersten Encle des Wolff"schen Körpers, wo die Anlagen der Querkanälchen noch nicht in den Wolff'schen Gang einmünden. Dort drüngen sich diese Anlagen, je weiter wir nach unten kommen, um so näher zusammen. Zuletzt scheinen sie zu einem ununterbrochenen Zellstrang zu verschmelzen, welcher sich zwischen Segmental- und Mittelplatte bis fast zur Eimmündung des Wolff"schen Ganges in die Cloake hinzieht. Es ist dies das Urnierenblastem oder die ,intermediare Zellmasse" der Autoren. Eine Uebereinstimmung mit den Ursegmenten kann auch an den untersten noch erkennbaren Segmenten nicht festgestellt werden.

Jedes einzelne Segment steht nun in Verbindung nach 3 Richtungen hin: mit den Elementen der Mittelplatte, den zukünftigen Peritonealepithelien; mit den Zellen des entsprechenden Ursegmentes; endlich läuft anch ein Fortsatz an die Wand der Aorta hin. Vom Wolft'schen Gang sind sie auf seiner ganzen Länge deutlich durch die Verschiedenheit der Zellen geschieden. Won der Stelle an, wo eine Segmentirung des Urnierenblastems wicht mehr zu erkennen ist, erscheinen anch die genannten Verbindungen ununterbrochen. Die beiden ersten Verbindungen deuten gewiss darauf hin, dass das Urnierenblastem Elemente sowohl von der Mittelplatte als von der Segmental- oder Urwirbelplatte bezieht. $\mathrm{Ob}$ dies der alleinige Ursprung desselben sei, oder ob ein Theil in loco entstehe, kann natürlich aus diesen Bildern nicht herausgelesen werden. Wahrscheinlich ist es aber a priori, dass das Urnierenblastem als Leiste der Mittelplatte und der Segmentalplatte entstehe und dann selbständig nach hinten zu wachse unter Erhaltung schmaler Verbindun- 
gen mit seinem Matterboden. Der nach der Aorta verlaufende Fortsatz bildet wohl die Anlage des für den Glomerulus bestimmten Gefässzweigchens.

Das Wachsthum des Wolff'schen Körpers geht demnach so vor sich, dass das Blastem, von oben beginnend, durch Segmentirung in die Anlagen der Querkanälchen zerfällt, diese dann mit vorschreitender Entwicklung nach obenhin, d. h. proximalwärts, sich Platz geben und ihre Verbindung mit dem Peritonealepithel und den Ursegmenten lösen. Am unteren Ende der Urniere entstehen also neue Harnkanälchen; durch diese Apposition findet das Wachsthum statt. Dieselbe dauert aber nur so lange, als das vorgebildete Urnierenblastem Bildungsmaterial liefert. Bei Embryo II ist es bereits aufgebraucht. Während dieses Wachsthums riickt die obere Grenze der Urniere proximalwärts bis sie den Lungenrand erreicht hat. Dies geschieht durch das Auseinanderweichen der bereits gebildeten Kanälchen nach oben hin und durch die Apposition neuer Kanälchen am unteren Ende; sodann findet, wie eine Vergleichung unserer beiden Embryonen zeigt, auch eine Verschiebung der Drüse in toto statt, indem die Einmündung des Wolff'schen Ganges in den Darm etwas nach oben rïckt (vgl. Fig. 1 u. 2). Trotzdem wir eine successive Bildung der Harnkanälchen von oben nach mten annehmen müssen, ist der Abstand derselben nicht etwa ein nach oben hin zunehmender; es wächst mithin die Drüise dort, wo die Kanälchen eine bestimmte Ausbildung erfahren haben, gleichmässig weiter im Verhältniss des allgemeinen Körperwachsthums. Zu oberst erfahren sie sogar, trotzdem dort die ältesten liegen - vielleicht in Folge der Einengung durch die V. cardinalis - eine leichte Verkümmerung. $\mathrm{Ob}$ in noch früheren Entwicklungsstadien (als unser Embryo I es zeigt) im ursprïnglichsten, also im jetzigen obersten, Theile der Urniere die Bildung der Kanälchen in anderer Weise vor sich gehe, so dass z. B. einzelne Kanälchen aus von vornherein isolirten Einwucherungen des Pleuroperitonealepithels entstehen, wie dies von einigen Forschern bei Thieren beobachtet worden ist (s. unten), kann aus unseren Bildern nicht bestimmt werden.

Der Umstand, dass, mit Ausnahme der beiden auf den Figuren 12 und 13 gegebenen, nicht ganz normal entwickelten, sämmtliche Querkanälchen-Anlagen vom Peritonealepithel gelöst sind und als ganz selbständige Gebilde in der Wolff'- 
schen Leiste liegen, zusammen mit der Thatsache, dass die Querkanälchen von Embryo I zu Embryo II ganz im Verhäitniss des Längswachsthums der Kürper auseinander gerilckt sind, beweist zur Genüge, dass a uf diesen Stadien ne ue Anlagen von Kanälchen vom Peritonealepithel aus, etwa zwischen den bereits gebildeten, nicht vorkommen und dass die Vermehrung derselben einzig und allein nur am unteren Ende stattfindet.

Mit Bezug auf die Entstehung der Windungen der Kanälchen steht so viel fest, dass sehr bald nach Abschnürung: der Anlage aus dem Blastem die drei Windungen zu unterscheiden sind; allerdings in einer Gestalt wie sie Fig. 12 zeig.t. Rasch bilden sie sich aber zu einem Grade der Vollkommenheit aus, auf welchem sie nicht mehr weit hinter den gewiss bereits funktionsfähigen des Embryo II stehen. Sie bilden von Anfang an ununterbrochene Kanäle, das heisst, es wird nicht jeder Schenkel für sich angelegt. Der erste Schenkel tritt schon in den ersten Entwicklungsphasen mit dem Wolff'schen Gang in Verbindung. Ein Entgegenwachsen der Wand des Wolff'schen Ganges ist unwalrscheinlich; es kann durch zufüllige Schnittrichtung des bereits einmündenden Kanälchens vorgetäuscht werden.

Was die Entstehung des Lumens in den Kanälchen betrifft, so geht aus meinen Präparaten mit Bestimmtheit herror, dass, wenigstens im unteren Theil der Urniere, nicht von Anfang an eine Lichtung vorhanden ist, die Kanälchen also nicht abgeschnurte Partien bereits vorhanclener Höhlen darstellen können. In demjenigen Abschnitte des Urnierenblastems, in welchem die Segmentirung in einzelne zu Kanälchen bestimmte Zellgruppen eben erst begomnen hat, ist von Andeutung an ein Lumen nichts vorhanden. Proximalwärts treffen wir zunächst auf solche Anlagen, welche im Centrum weniger dichte Gruppirung der Zellen wahrnehmen lassen; es ist dies bereits eine Andeutung an eine Lichtung. Die Elemente stellen sich dann radiär gegen das Centrum; die Zellkerne weichen etwas zuruick in centrifugaler Richtung und endlich zeigt sich eine dentliche Lichtung (s. Fig. 3). Dieselbe ist wenig grösser als der Umfang einer Zelle, durch ganz scharfe Contouren begrenzt und enthält im Innern ofters eine Substanz, welche mehr als andere Parthien das Eosin behält. Diese Billerfolge erweckt den Eindruck, als 
ob die Lichtung durch Auseinandertreten der Zellen - vielleicht infolge Secretion ciner Flüssigkeit - entstehe.

Wie bereits oben angedeutet, bekommen wir bei der Entstehung der Glomeruli Bilder, welche anf eine Bildung des Lumens durch Zerfall der centralen Zellen hinweist: Zellhaufen mit centraler Lichtung, welche durch stark gekörnte, schlecht fürbbare Zellen unregelmässig und nicht scharf begrenzt ist. Diese Bilder sprechen gegen die Ansicht von Bornhaupt und Braun, welche (beim Hühnchen und den Reptilien) annehmen, dass das erste Blut der Malpighi'schen Körperchen in loco entstehe, durch Umwandlung der centralen Zellen in Blutkörperchen oder durch Abschniurungen ron der Wand. Ich habe auch (s. oben), ganz im Gegensatz zu diesen Autoren, hervorgehoben, dass schon bevor die Glomeruli Blut enthalten, Gefäissanlagen von Aorta und Cardinalvene zu ihnen herantreten.

Auch über die Entstehung der Urnierenkanülchen sind die Forscher verschiedener Ansicht.

Waldeyer erklärt sie für directe Sprossen des Umierenganges. $\mathrm{H}$ is macbt bei der Beschreibung des Embryo a die Bemerkung: die Wanddicke des Wolff'schen Ganges betrage fast das Doppelte von derjenigen des spiiteren Wolff'schen Ganges mol dies wiirde ihn veranlassen, auf Entstehung der Kanilchen aus dem Wolf'schen Gange dureh Verdünnung und Faltung dor Wand zu schliessen, wenn nicht, fügrt er hinzu, für sïmmtlicho Wirbelthicre clio Entstehung desselben aus dem Epithel der Leiste nachgewiesen wire. Doch leitet er selbst in seinen "Untersuchungen über die erste Anlage des Wirbelthierleibes (1868)“ die Querkaniilchen gerade wie den Wolff'schen Gang: aus clen Urwirbelkernen ab.

Bornhaupt ist der Ansicht, dass die Urnierenkanälchen sich aus dem Urnierenblastem, jener zwischen Mittel- und Urwirbelplatte sich hinziehenden Zellmasse, die aus dem Mesoderm hervorgegangen ist, herausdifferenziren. Remak, Egli, Balfour, Bernoff, v. Mihalkovicz vertreten die nämliche Anschauung.

M. Braun findet bei den Reptilien die Entstehung der Kanälchen aus soliden Sprossen des Peritonealepithels in die Mittelplatte hinein. Die Sprossen, welche der Zahl nach den Körpersegmenten entsprechen, wandeln sich zu Blaschen um. Diese treten durch einen Fortsatz mit dem Wolff'schen Gang in Verbindung, verlieren den Zusammenhang: mit dem Peritonealepithel und werden zu den Malpighi'schen Körpern, während jene Fortsätze die Kanälchen darstellen. Bei den Anamnia bleibe die Verbindung der Bläschen (Segmentalbläschen nennt er sie) mit dem Peritonealepithel das ganze Leben hindurch.

Kölliker lässt die Urnierenkanälchen beim Hühnchen als keulen- 
oder kolbenförmige Divertikel von der Bauchhöhle aus entstehen. Die Oeffnung in die Bauchhöhle ist rundlich, klein, sehwer erkennbar. Die Verbiudung mit der Bauchhöhle löst sich erst, nachdem die Schlituche mit dem Wolff'schen Gang sich verbunden haben. Beim Kaninchen entstehen sie als kolbentörmige Wucherung der Mittelplatte ohme Höhlung.

Siemerling leitet die Kanälchen ebenfalls rom Peritonealepithel $a b$.

Renson unterscheidet zwisehen vorderer und hinterer Partie des Wolff'schen Körpers. Vorn entstehen die Urnierenkaniilchen aus Zellstrïngen, welche vom Pleuroperitonealepithel ausgehen; hinten differenziren sie sich aus der "masse intermediaire", welehe ihrerseits durch Wucherung des Pleuroperitonealepithels entstanden ist, heraus. Die Zellen derselben gruppiren sich um kleine Lacunen, welche Ueberreste der Verbindungskanäle zwischen Urwirbelhöhle mul Coelom sind, und bilden so die Kanialchen mit Lumen (Untersuchungen an Hühnchen, Kaninchen, Ratten).

Sed"gwick nimmt auch vorn directe Entwicklumg ans dem Peritonealepithel, hinten solche aus dex intermediaren Zcllmasse, welche vom Epithel stammt, an. Die secundären and tertiaren Kanälchen seien Ausstïlpungen cles Wolff'schen Gingres.

Janosik leitet einen Theil der Kanalchen vou isolirten Sprossen des Peritonealepithels ab. Ein anderer Theil entstehe dadurch, dass das Urnierenblastem, eben jene "masse intermédiaire", in Gruppen zerfalle, welche sich durch Einschmelzung der centralen Zellen in Bläschen umwandeln. Das Urnierenblastem gehe aus dem Peritonealepithel hervor, wachse aber nach hinten eine Strecke weit frei, ohue Verbindung mit dem Epithel, fort. Die secundiiren Kanälchen entstehen aus den primären, die tertiären aus den secundären; neue Einstülpmng des Epithels kommt nicht vor.

Hertwig sagt in seinem Lehrbuche, die Untersuchungsresultate der Forscher zusammenfassend: Die Urnierenkanälchen entstehen dadurch, dass aus dem Epithel der Leibeshöhle (mittleres Keimblatt) hohle oder solide Zellstränge, zuweilen in segmentaler Anordnung hervorsprossen und dem seitlich gelegenen Wolff'schen Gang in querer Richtung entgegenwachsen. Bei den höhern Wirbelthieren ist die Entwicklung des Wolff'schen Körpers eine gewissermassen verkïrzte, insofern als an ihrem hintern Abschnitt sich ein Hervorsprossen einzelner Urnierenkanailchen aus dem Epithel der Leibeshöhle nicht beobachten lässt, diese sich vielmehr aus einem zusammenhängenden, vom mittleren Keimblatt abstammenden Zellenstreifen, aus einem Urnierenblastem, zu sondern scheinen. Bei einem Theil der amnionlosen Wirbelthiere (Amphibien, einige Selachier) bleibt die Urniere mit der Leibeshöhle durch zahlreiche Flimmertrichter (Nephrostome) in offener Verbindung, während bei allen Amnioten die Urnierenkanälchen einen genetisch begründeten Zusammenhang mit der Leibeshöhle durch Schwund der Flimmertrichter frühzeitig aufgeben. 


\section{Erklärung der Abbildungen auf Tafel V u. VI.}

Fig. 1. Sagittaler Medianschnitt von Embryo I, durch Reconstruction gewonnen; in 50facher Vergrösserung.

Schraffirt ist die Hautdecke; hell schattirt das Centralnervensystem; dunkler das Aortensystem und die Umbilicalarterie; schwarz der Verdauungstractus mit seinen Anhäingen.

H. Herz; Lg. Lungenanlage; Lb. Leberanlage; d. o. e. ductus omphalo-entericus; Cl. Cloake; All. Allantois; Wg. Wolff'scher Gang; A. u. Arteria umbilicalis; 2. und 3. Kiemengang; Am. Amnios.

Fig. 2. Sagittaler Medianschnitt von Embryo II, durch Reconstruction gewonnen; in 26facher Vergrösserung.

Schattirung wie bei Fig. 1 .

Bezeichnung wie oben. O. Ohranlage; A. Auge; P. Pankreasanlage; $N$. Nierenanlage.

Fig. 3, 4, 5, 6 zeigen von Embryo I den Wolff'schen Gang in seinem untersten Verlaufe. Die Zeichnungen sind nach Photographien in ca. 250facher Vergrösserung angefertigt.

Fig. 3 ist aus einem tangentialen Schnitt des Steisses, durch welchen die Aorta, der Wolff'sche Körper und sein Ausfïhrung'sgang der Länge nach getroffen sind. Das Bild stellt nur die eine Hälfte des Schnittes, und diese nur theilweise, dar. Ao. Aorta; Hk. Anlage der Harnkanälchen der Urniere; Wg. Wolff'scher Gang; Lh. Leibeshöhle (von der gerade noch das unterste Ende getroffen ist); Ep. Epidermis.

Fig. 4 gibt ein Stiick aus einem um $0,14 \mathrm{~mm}$ distal gelegenen Schnitt. Die Leibeshöhle ist stärker getroffen; Aorta, Wolff'scher Gang und Urnierenkanälchenanlage sind schief getroffen. Die Anlage des Wolff'schen Ganges (Wg:) steht mit der Epidermis in Verbindung. Uw. Urwirbel (nahe an einem Segmen. taleinschnitt gețroffen).

Fig. 5. Sehnitt vom Schwanzende $0,29 \mathrm{~mm}$ weiter distal. Rm. Rückenmarksanlage ; D. Darm oder Cloake; U. E. untere Extremität. Der Wolff'sche Gang (Wg.) steht mit der Epidermis in Zusammenhang.

Fig. 6. 3 Schnitte weiter distal. Bezeichnung wie vorhin. Die Anlage der unteren Extremität ist tangential getroffen und verschwindet in den nächsten Schnitten ganz.

Fig. 7 ( $a, b, c, d, e, f)$ veranschaulichen die Vereinigung der Nierengänge mit den Wolf'schen Gängen und ihre gemeinsame Einmündung in die Cloake bei Embryo II. Ng. Nierengang; Wg. Wolff'scher Gang; D. Darm; Lh. Leibeshöhle. A. u. Arteria uterina; Cl. Cloake; S. ug. Sinus urogenitalis; All. Allantois. 
172 Hans Meyer: Die Entwickl. d. Urnieren beim Menschen.

Auf Fig. f bezeichnet das an der Cloake unten abgeschnïrte Stückchen den Durchschnitt eines kleinen Blindsackes, welcher auf der ventralen Seite der Cloake sich nach dem Schwanzende zu ausstülpt und wohl bei der Bildung des Afters eine Rolle spielt.

Fig. 8, 9, 10, 11. Quersehnitte der Wolff'schen Leiste von Embryo II. $8,10,11$ von der linken, 9 von der rechten Seite. Ao. Aorta; Lh. Leibeshöhle; V. c. vena cardinalis; M. Mesenterium; Bw. seitliche Bauchwand. Gez. mit Hartnack 7; Oc. 3 halb ausgezog. Tubus.

Fig. 8 vom ersten, d. h. obersten Viertel des Wolff'schen Körpers. Die v. card. dräingt Harnkanillchen und Glomerulus etwas nach innen. In noch höher gelegenen Schnitten ist das noch in viel höherem Grade der Fall. Die querdurehschnittenen Harnkanächen gehören der zweiten Windung an; sie sind stark ausgeweitet; ihre Wandung ist einschichtig.

Fig. 9 aus dem dritten Viertel des Wolff'schen Körpers. Die v. carl. hat sich bedentend zurückgezogen. Uebergang der ersten Windung des Harnkanallehens in die zweite. Glomerulus ein mit Blutkörperchen angefülltes, e in kammeriges Sïckchen (weder in den vorangehenden, noch in den nachfolgenden Schnitten ist etwas von einem Septum im Glomerulus zu sehen).

Fig. 10, ebenfalls aus dem dritten Abschnitt. Ganz ähnliches Verhalten des Glomerulus wie vorhin. Zweite Windung: durch Verdickung ihrer Wandungen spindelförmig' aufgetrieben; Uebergang in Malpighi'sche Kapsel.

Fig. 11, vom untersten Viertel. Wolff'scher Gang ganz nahe am Glomerulus. Letzterer erst in Bildung begriffen, noch blutlos; durch Zerfall der centralen Zellen bildet sich ein Lumen.

Fig. 12 u. 13 geben Durchschnitte der Wolff'schen Leiste des Embryo II von der linken Seite. Sie sind nach Photographien in circa 250facher Vergrösserung (Fig. 13 etwas grösser) hergestellt und zeig'en, wie ein Zusammenhang der Urnierenkanälchen mit dem Peritonealepithel, aus der Zeit der Entstehung derselben, erhalten bleiben kann. Der Unterschied im Bau des Wolff'schen Ganges ist auf diesen beiden Zeichnungen sehr deutlich. Fig. 12 stammt ungefïhr aus der Mitte der Urniere; Fig. 13 vom obern Ende.

Bezeichnung wie vorhin. Uwh. Urwirbelhöhle (Segmentalhöhle). 